\title{
Effect of Intervention Educational Programs on Improving Quality of Life among Overweight/Obese University Students in Gaza Strip
}

\author{
Ahmed A. Najim \\ Faculty of Intermediate Studies, University of Palestine, Gaza, Palestine \\ Email: ahmednajim99@yahoo.com
}

Received 9 October 2014; revised 8 November 2014; accepted 20 November 2014

Copyright (C) 2014 by author and Scientific Research Publishing Inc.

This work is licensed under the Creative Commons Attribution International License (CC BY). http://creativecommons.org/licenses/by/4.0/

\section{(c) (i) Open Access}

\begin{abstract}
Background: Overweight and obesity are among the most frequently encountered multi-factorial disorders in most populations of the world. In addition, to its health impacts, overweight/obesity leads to many health problems which reflect on the university students' physical, psychological, social and environmental aspects of their quality of life. The study aim was to evaluate the effect of an educational program on improving quality of life of overweight/obese university students in Gaza strip. Materials and Methods: quasi-experimental nonequivalent pretest-posttest control group design utilized in this study 74 and 69 students in the intervention and control group respectively. The study conducted at Islamic university of Gaza and data were collected in two stages before and after five months from the application of the educational program, using interviewing questionnaire and world health organization quality of life-BREF instrument; pre-post test and body mass index were calculated. Results: the study results revealed that overall students' knowledge for posttest was significantly higher than pretest (p-value $\leq \mathbf{0 . 0 5}$ ). Overall, mean score of quality of life after the program was significantly $(p$-value $=0.001)$ greater than before and greater than control group for all domains. Conclusion: The study concluded that the health educational intervention program had positive effects on knowledge, practices and attitudes regarding overweight/obesity with improving university students' mean score of quality of life.
\end{abstract}

\section{Keywords}

Education Program, Quality of Life, Overweight, Obesity, University Students 


\section{Introduction}

Overweight/obesity is one of the leading preventable causes of death worldwide. As the rates of adult and childhood obesity increase, authorities' views on overweight/obesity is one of the most serious public health problems of the 21 st century [1]. The World Health Organization (WHO) predicts that overweight/obesity may soon replace more traditional public health concerns such as under nutrition and infectious diseases as the most significant cause of poor health [2]. The economic cost of obesity and its associated co-morbidities are skyrocketing which are beyond the capacity of the best health care system in the world [3]-[5].

Overweight/obesity prevention programs have been founded to reduce the cost of treating overweight/obesityrelated disease. Researchers therefore conclude that reducing obesity may improve the public's health [6]. Community health nurse $(\mathrm{CHN})$ roles' particularly well being placed to take action to promote healthy behavior, and to help adult to access at various stages of their lives and their ability to accomplish their roles. Nowadays, changes in the health care system are increasingly shifting the roles and responsibilities of professional nurses toward the area on health promotion [7]. Nurses have an ideal opportunity to enhance health-promoting activities in order to reduce the risks of being overweight/obese and anyhow there are many roles that can practice by the $\mathrm{CHN}$, as health promoter to prevent overweight/obesity [8].

The primary aim of the current study was to evaluate the effect of an educational program on improving quality of life of overweight/obese university students in Gaza strip.

It is obvious that overweight/obesity is still an important problem of public health in the Gaza strip (GS) as it is in the world and will affect health of people in the future. The national strategic health plan in Palestine was concerned with overweight/obesity control and prevention in both governmental and nongovernmental organizations through its policy objectives to reduce the proportion of people severely overweight/obese by developing educational programs emphasizing the importance of regular physical activities and fitness/ promoting healthy lifestyle and behavior modification.

For thousands of years obesity was rarely seen [9]. It was not until the 20th century that it became common; in 1997 WHO formally recognized obesity as a global epidemic feature [10]. As for 2005 the WHO estimated that at least 400 million adults $(9.8 \%)$ were obese, with higher rates among women than men [11]. The rate of obesity also increases with age at least up to 50 or 60 years old [12].

In the Eastern Mediterranean Region (EMR), the status of overweight/obesity has reached an alarming level. A prevalence of $3 \%-9 \%$ overweight and obesity has recorded among preschool children, while that among schoolchildren was $12 \%-25 \%$. A marked increase in obesity generally has noted among adolescents, ranging from $15 \%$ to $45 \%$. The proportion of overweight and obesity (BMI $25 \mathrm{~kg} / \mathrm{m} 2$ ) among men ranged from $30 \%$ to $60 \%$, while among women it ranged from $35 \%$ to $75 \%$ [13].

The researcher noticed the problem of overweight/obesity through clinical experience and its significance derived from the available statistics that reflected high prevalence of overweight/obesity among Palestinian population as indicated by the Palestinian Ministry of Health (PMOH). The prevalence of obesity among female and male was $48 \%$ and $30 \%$ respectively, while the overweight prevalence for female was $21.5 \%$ and for male was $36.4 \%$ [14]. In addition to its health impacts, overweight/obesity leads to many health problems and it is reflecting on the students' physical, psychological and social aspects of their QoL [12].

Therefore, this research study would be of great value for nursing practice by testing an educational intervention program of overweight/obesity by the university students as an important strata target from the university population. Students' knowledge of overweight/obesity and their QoL domains will be explored by the research study. CHN, nursing administrators and nurse educators, this study may help in adopting evidenced based for decision making regarding implementation of such program to improve QoL of overweight/obese university students' in the GS.

In the GS, there were lacks of data about obesogenic factors, which were important in defining and understanding the high risk factors that should be targeted for future modifications in public health interventions. There were few explorative studies conducted to estimate the prevalence of overweight/obesity particularly among university students. In the Arab countries, few studies are available regarding the determinants of obesity particularly among university students. These studies found that factors associated with obesity were age, sex, education, marital status, smoking, physical activity, parental obesity, dietary habits and socio-cultural factors [13] [15]-[19].

Due to overweight/obesity and its associated QoL modifying risk factors the researchers choose to conduct 
this study to identify the magnitude of the problem, to highlight the associated QoL modifying risk factors, which may cause overweight/obesity, to develop and implement an educational intervention program and also to suggest recommendations for prevention and controlling of overweight/obesity.

\section{Material and Method}

\subsection{Study Design and Population}

The current study was Quasi-experimental, nonequivalent group, pretest-posttest design, was utilized in this study. With this design, both the control group and the intervention group compared however, the groups chosen and assigned out of convenience rather than through randomization. The study conducted at the IUG, which considered the largest university in GS.

\subsection{Sample and Sampling}

Multistage probability proportional random sampling technique was utilized. The researcher obtained lists of the university students' aggregated by gender and college. Then, systematic proportional random sample was been chosen from each college (students' lists) in proportion to the number of students $(5 \%)$. The total number of the selected students was 1032 representing $5 \%$ of the university students. Weight, height and other relevant data were obtained. Among the selected 1032 university students, 155 university students were overweight/obese and were included in the study groups, 79 university students were included in the intervention group and 76 university students in the control group, both the control group and the intervention group are compared however, the groups are chosen and assigned out of convenience rather than through randomization.

Five students from the intervention group dropped out from the study either due to their concern for the university exams (two students) or transporting abroad (three students). Therefore, the number of students in the intervention group at the end of the study was 74 and seven students from the control group also were dropped also for several reasons such as lack of response or some of them not responding to their mobiles and others do not have enough time. Therefore, the total number of control group at the end of the study was 69 students. Thus, 143 students were completed the study procedure with a response rate of $92.2 \%(143 / 155)$.

\subsection{Aims and Objectives}

The main objectives of the present study were to determine assess the overweight/obese university students' knowledge, attitude and practice towards overweight /obesity to develop and implement health education program to improve the QoL of overweight/obese university students, and to evaluate the effect of the educational program on improved the QoL among overweight/obese university students in GS.

\subsection{Methodology}

The collected data were been analyzed using statistical package for the social science (SPSS) version 16. All reported $\mathrm{p}$ values compared to a significant level of $5 \%$; differences were been considered statistically significant at $\mathrm{p} \leq 0.05$.

\subsection{Eligibility Criteria}

\section{Inclusion Criteria}

1) Students with BMI $\geq 25$ (cutoff point $B M I \geq 25$ );

2) Students with no medical history;

3) Students with no medication and no current diseases.

\subsection{Tools of the Study}

The following study tools were used, the researcher structured them after reviewing related literature and the others were adopted, tested and piloted:

1) Structured interviewing questionnaire designed and developed by the researcher.

2) The pre-post test was used to examine the students' knowledge, attitudes and practices related to overweight/obesity before and after administering the health educational program, which was constructed by the re- 
searcher based on the revised articles, books, related literature.

3) Anthropometric measurements

The participants weighed at baseline and five months later.

4) The WHOQOL-BREF is a 26-item instrument consisting of four domains: physical health (7 items), psychological health (6 items), social relationships (3 items), and environmental health (8 items); and two overall QoL and general health items.

Scoring and Interpretation: Using a 5-point scale for each item, the client circles the number that best represents their opinion, based on their life over the previous two weeks. The 5-point scale ranges from "Not at all" (a score of 1) through to "Completely" (a score of 5). Higher scores indicate a better QoL.

5) Education program

An educational program and the educational booklet designed by the researcher after reviewing the related literature. During the implementation of the educational program the researcher had complied with the distribution the educational booklet and of handouts on the program sessions, which prepared by the researched during the meetings of members of the study sample.

\subsection{Ethical and Administrative Issues}

Approval of the study was sought from Cairo university faculty of nursing and from the setting of the study at IUG. University students selected from those who wishing to participate based on the inclusion criteria. Informed consent was been given to each one prior to filling the questionnaire and written agreement was obtained from each one.

\section{Results}

Results of the current study will presented according the following sequence:

Table 1 indicates that study hours/day means and SD was $3.38 \pm 1.8 \& 3.09 \pm 2.07$ with a statistically significant difference between intervention and control group respectively with $\mathrm{p}$-value $=0.037$, at $\alpha=0.05$.

Section I: Description of students' socio-demographic characteristics

Table 2 shows the number of hours the students sleep at night more than 8 hours before the program equal to $87.8 \%$ compared to $78.4 \%$ \& $71.0 \%$ after for intervention and control group respectively. Chi-Square $=6.251$ with $\mathrm{p}$-value $=0.019$. Therefore, there is significant strong relationship between intervention and control groups and number of hours they sleep at night.

Section II: Data related to KAP of the study sample and statistical relations between KAP of overweight/ obese students

Table 3 shows that there was proportional significant differences between the OW and obese students in both groups in BMI posttest than pretest $70.3 \%$ \& $29.7 \%$ vs. $50.7 \%$ \& $49.3 \%$ for intervention and control group respectively, with statistical significant relationship with p-value $=0.001$.

As shown in Table 4 there is significant difference in students' practices of intervention group pretest and posttest and between intervention and control group posttest in breakfast taking, beverages drinking, sweetened drink, fast foods taking, checking labels $\&$ taking meal with $p$-value $=0.001$. There is a statistically significant relationship between the above-mentioned variables.

\section{Section III: Students' overall QoL rating and satisfaction with their health}

This section presents student's overall perception of QoL and an individual's overall perception of their health, which had examined separately by asking two questions to the students.

Table 5 reveals that $18.9 \%$ of students rated that their overall QoL were very good compared to $33.8 \%$ \& $20.3 \%$ after for intervention and control groups respectively. In relation to how students were satisfied with their health $8.1 \%$ of intervention group students' perceive that, their health was very good compared to $24.3 \% \&$ $7.2 \%$ after for control groups.

\section{Discussion}

\subsection{Socio-Demographic Characteristics of the Study Sample}

Socio-demographic characteristics of the study sample is a known determinant of overweight/obesity, in the present study about two third of students either in intervention or in the control group were having a positive 
Table 1. Distribution of the study sample of the university students based on socio-demographic characteristics $(n=143)$.

\begin{tabular}{cccccc}
\hline Variable & & Intervention $(\mathbf{n}=\mathbf{7 4})$ & Control $(\mathbf{n}=\mathbf{6 9})$ & t-test & p-value \\
\hline Family history of OW/obesity & No $(\%)$ & $53(71.6)$ & $49(71)$ & 0.486 & 0.62 \\
Residence: Urban & & $57(77.0)$ & $58(84.1)$ & & 0.08 \\
Rural & No $(\%)$ & $17(23.0)$ & $11(15.9)$ & & \\
Number of family member & Mean $( \pm \mathrm{SD})$ & $8.4(2.6)$ & $8.01(2.4)$ & -0.754 & 0.452 \\
Study hours/days & Mean $( \pm \mathrm{SD})$ & $3.38(1.8)$ & $3.09(2.07)$ & -0.885 & $0.037^{*}$ \\
\hline
\end{tabular}

${ }^{*}$ The relationship is statistically significant level at 0.05 .

Table 2. Distribution of study sample according to no. of hours they sleep at night before and after implementation of the program $(n=143)$.

\begin{tabular}{|c|c|c|c|c|c|c|c|c|}
\hline \multirow{3}{*}{$\begin{array}{c}\text { Sleeping } \\
\text { hours/night }\end{array}$} & \multicolumn{4}{|c|}{ Intervention $(n=74)$} & \multicolumn{2}{|c|}{ Control $(n=69)$} & \multirow{3}{*}{$\chi^{2}$ Test } & \multirow{3}{*}{ p-valuc } \\
\hline & \multicolumn{2}{|c|}{ Pre } & \multicolumn{2}{|c|}{ Post } & \multirow{2}{*}{$\mathbf{n}$} & \multirow{2}{*}{$\%$} & & \\
\hline & $\mathbf{n}$ & $\%$ & $\mathbf{n}$ & $\%$ & & & & \\
\hline$\leq 8 \mathrm{hrs}$ & 65 & 87.8 & 58 & 78.4 & 49 & 71.0 & 6251 & $0010^{*}$ \\
\hline$>8 \mathrm{hrs}$ & 9 & 12.2 & 16 & 21.6 & 20 & 29.0 & 0.201 & 8.078 \\
\hline
\end{tabular}

${ }^{*}$ The relationship is statistically significant level at 0.05 .

Table 3. Distribution of university students according to BMI values between intervention and control groups pre and post application of the program $(n=143)$.

\begin{tabular}{|c|c|c|c|c|c|c|c|c|}
\hline \multirow[b]{2}{*}{ BMI } & \multicolumn{2}{|c|}{ Pre $(n=143)$} & \multirow[b]{2}{*}{$\chi^{2}$ test } & \multirow[b]{2}{*}{ p-value } & \multicolumn{2}{|c|}{ Post $(n=143)$} & \multirow[b]{2}{*}{$\chi^{2}$ test } & \multirow[b]{2}{*}{ p-value } \\
\hline & $\begin{array}{l}\text { Intervention } \\
(n=74)(n) \%\end{array}$ & $\begin{array}{c}\text { Control } \\
(n=69) \%\end{array}$ & & & $\begin{array}{l}\text { Intervention } \\
(n=74) \%\end{array}$ & $\begin{array}{c}\text { Control } \\
(n=69) \%\end{array}$ & & \\
\hline$<25$ & 0.0 & 0.0 & & & (12) 16.2 & 0.0 & & \\
\hline$\geq 25-29.9$ & (52) 70.3 & (35) 50.7 & 5.725 & $<0.01^{*}$ & (41) 55.4 & (31) 44.9 & 18.14 & $<0.001^{*}$ \\
\hline$\geq 30$ & (22) 29.7 & (34) 49.3 & & & (21) 28.4 & (38) 55.1 & & \\
\hline
\end{tabular}

${ }^{*}$ The relationship is statistically significant level at 0.05 .

Table 4. Selected diet practices by the students before and after application of the health educational program $(n=143)$.

\begin{tabular}{|c|c|c|c|c|c|c|c|c|c|c|}
\hline \multirow{3}{*}{ Variable } & \multicolumn{4}{|c|}{$\begin{array}{c}\text { Intervention } \\
(n=74)\end{array}$} & \multirow{2}{*}{\multicolumn{2}{|c|}{ McNemar test }} & \multirow{2}{*}{\multicolumn{2}{|c|}{$\begin{array}{l}\text { Control } \\
(n=69)\end{array}$}} & \multirow{2}{*}{\multicolumn{2}{|c|}{$\chi^{2}$ test }} \\
\hline & \multicolumn{2}{|c|}{ Pre-test } & \multicolumn{2}{|c|}{ Post-test } & & & & & & \\
\hline & No. & $\%$ & No. & $\%$ & Value & $\mathrm{P}$-value & No. & $\%$ & Value & P-value \\
\hline Fruits consumption/daily & 5 & 6.8 & 6 & 8.1 & 0.054 & 0.900 & 5 & 7.2 & 0.037 & 0.847 \\
\hline Breakfast taking/daily & 26 & 35.1 & 64 & 86.5 & 34.225 & $<0.001^{*}$ & 21 & 30.4 & 46.532 & $<0.001^{*}$ \\
\hline Beverages drink/daily & 72 & 97.2 & 62 & 83.8 & 26.342 & $<0.031^{*}$ & 61 & 88.4 & -0.105 & 0.9165 \\
\hline Sweetened drink/daily & 39 & 52.7 & 18 & 24.3 & 3.570 & $<0.001^{*}$ & 40 & 58 & 1.915 & $0.050^{*}$ \\
\hline Water drinking 2 - 3 liters/daily & 23 & 31.1 & 27 & 36.5 & 1.057 & 0.29 & 22 & 31.9 & 1.163 & 0.245 \\
\hline Fast foods taking/daily & 14 & 18.9 & 6 & 8.1 & 2.259 & $<0.024^{*}$ & 15 & 21.7 & 2.465 & $<0.014^{*}$ \\
\hline Checking labels & 37 & 50 & 60 & 81.1 & 4.271 & $<0.001^{*}$ & 32 & 46.4 & 4.362 & $<0.001^{*}$ \\
\hline Taking meal regularly & 35 & 47.3 & 39 & 52.7 & 0.575 & 0.567 & 27 & 39.1 & 2.035 & 0.361 \\
\hline
\end{tabular}

${ }^{*}$ The relationship is statistically significant level at 0.05 . 
Table 5. Comparison between the overall QoL perceptions of students' and the perception of their health for the study sample before and after the application of the program $(n=143)$.

\begin{tabular}{|c|c|c|c|c|c|c|c|}
\hline \multicolumn{3}{|c|}{ Rating quality of life } & Very bad & Bad & Moderate & Good & Very good \\
\hline \multirow{2}{*}{ Intervention $(\mathrm{n}=74)$} & Pre & No (\%) & $1(1.4)$ & $3(4.1)$ & $18(24.3)$ & $37(50.0)$ & $14(18.9)$ \\
\hline & Post & No (\%) & $1(1.4)$ & $1(1.4)$ & $10(13.5)$ & $37(50.0)$ & $25(33.8)$ \\
\hline Control $(n=69)$ & \multicolumn{2}{|c|}{ No (\%) } & $2(2.9)$ & $4(5.8)$ & $15(21.7)$ & $34(49.3)$ & $14(20.3)$ \\
\hline \multicolumn{8}{|c|}{ Health satisfaction } \\
\hline \multirow{2}{*}{ Intervention $(\mathrm{n}=74)$} & Pre & No $(\%)$ & $3(4.1)$ & $22(29.7)$ & $17(23.0)$ & $26(35.1)$ & $6(8.1)$ \\
\hline & Post & No (\%) & $1(1.4)$ & $5(6.8)$ & $10(13.5)$ & $40(54.1)$ & $18(24.3)$ \\
\hline Control $(n=69)$ & \multicolumn{2}{|c|}{ No (\%) } & $7(10.1)$ & $13(18.8)$ & $21(30.4)$ & $23(33.3)$ & $5(7.2)$ \\
\hline
\end{tabular}

family history of overweight/obesity (Table 1). This finding indicates that overweight/obesity runs in families and may suggest, in a limited way, that there are genetic aspects for the development of overweight/obesity. Data from previous studies highlighted the influence of positive family history as a significant contributor of overweight/obesity, this agrees with several findings as Al-Rukban [20] showed that presence of obesity among family members increased the risk of obesity by 2 to 4 times. Poirierha, Giles and Bray [21] revealed that like many other medical conditions, overweight/obesity is the result of interplay between genetic and environmental factors. Several studies concurred with this result. Mo-suwan, Tongkumchum and Puetpaiboon [22] found that the risk for obesity in child increased 2 - 3 folds if having family history of obesity, while Terres et al.'s study [23] was assuring that result as well.

In regard to study hours/day the mean $\pm \mathrm{SD}$ was $3.38 \pm 1.8$ and $3.09 \pm 2.07$ with a statistically significant difference between intervention and control group respectively (Table 1). So, the longer the period that the students assume to sit was been positively related to occurrence of overweight/obesity, the researcher explained that for overweight/obese students were less physically active and in addition they consume more snacks while sitting with high sugar and fat contents. The results of the current study were consistent with these of a study conducted by Khader et al. [24] found that the prevalence of overweight/obesity is more if sitting more than two hours/day and Al Sabbah et al. [25] also found that of obese boys were significantly less physically active than overweight.

With regard to sleeping hour at night, study results revealed that most of students slept at night less than 8 hours compared to majority of students after the program. In addition, the proportion of sleep at night more than 8 hours equals to less than one fifth of students compared to more than one fifth after the program with a statistical significant relationship with p-value $\leq 0.05$ (Table 2). Therefore, the increase rate of overweight/obesity could explained that if the person sleep less than eight hours over an extended period of time the metabolism will slow, and if possible sleep for more than eight hours for the best calorie-burning benefits which was not achieved by the vast majority of students in the current study.

This was in agreement, with the study that conducted by Layton and Julia [26] which revealed that the leptin hormone is intricately involved in the regulation of appetite, metabolism and calorie burning which it's level increases within 7 - 9 hours after sleep. Therefore, the decrease in leptin brought on by sleep deprivation can result in a constant feeling of hunger and a general slow-down of metabolism. College students often do not get adequate sleep. It is recommended that adults get at least eight hours of sleep each night National Sleep Foundation [27], yet the majority of students get only 6.8 hours of sleep per night. Furthermore, a study conducted at Stanford University on undergraduate and medical students found that $80 \%$ of students are sleeping deprived according to Kotler [28]. Thus, it appears that lack of sleep is a problem among college students. In addition, to overweight/obesity, getting little sleep has also been associated with poorer academic performance as conclusion of Pilcher and Walters's study [29].

\subsection{Knowledge, Attitude and Practice of the Study Sample and Statistical Relations between KAP of Overweight/Obese University Students and the Effect of the Health Intervention Educational Program}

The current data demonstrated that, more than two third of the students' in intervention group were overweight 
whereas; less than one third of them were obese, before application of the program whereas; after application of the program the overweight became slightly more than half, while obese students became slightly more than one fourth. On the other hand, the percentage of students who moved from either overweight or obesity and became within the normal range of BMI reached around one sixth of students after the application of the program (Table 3).

Therefore, the improvement that occurred on BMI of overweight and obese students in the intervention group was directly been related to the effectiveness of program sessions for the students. On the other hand, there were some improvements of overweight student' in control group from $50.7 \%$ to $44.9 \%$ which from the researcher point of you were related to reactive effect of the pretest where they perceived the seriousness of overweight/ obesity and threat to their health. The researcher have established that improvement in knowledge, attitudes or behavior have resulted from participation in overweight/obesity education program.

The results of the current study are in agreement and similar to the results reported by Haines et al. [30] in the 12-week Virtual Walking and Wellness Program at college campus. Pre- and post-evaluations of self-reported levels of physical activity were significantly different $(\mathrm{p} \leq 0.001)$. These results indicate that Mississippi in Motion/Bulldogs in Motion participants reported becoming more physically active while decreasing body weight and BMI.

The results of the current study disagree with these findings support evidence by Hart et al. [31] and Villareal et al. [32] that persons who are obese are at an increased risk for developing these life-threatening conditions. In addition, the health risks associated with obesity are more severe than in persons who are overweight, thus the overweight participants may not have felt their weight was a health risk which may be cause of their increased perception of very good or excellent health [31] [32].

Habit of water drinking $2-3 \mathrm{~L} /$ day found in about one third of students before and improved therefore after and became slightly less than two fifth. Checking labels before food consumption practiced by half of students before, improved therefore after, and became vast majority of students. Regarding beverages drinking and sweetened drink found in slightly more than nine tenth of students and slightly more than half of students before these two habits corrected to most and slightly less than one quarter of students after the program. With regard to meal regularly, this study revealed that slightly more than half of students eat irregular meals before compared to slightly less than half after the program (Table 4).

This could explain that the students have very poor diets and this habit tied with their lifestyles. Palestinians use bread with every meal with as spoon for eating. In addition, a higher proportion of students concentrate on fried food as their main dish and drink soft drinks, rich in refined sugars, during the day. Furthermore, a significant proportion of students prefer eating chicken to lean meat. A higher proportion of Palestinians consume, bread, falafel, humus and fava beans (foul) with sweetened tea at breakfast and supper daily. Fresh vegetables and fruits were been taken on average twice a week. This indicates the quantitative significance of sweet-fat combination foods in promoting a passive over-consumption of energy. In addition, various factors determine college student's selection of food. These factors include shortage of time, convenience, cost, taste, health, physical and social environment and weight control. Eating habits tend to become worse during college and young adulthood due to the fact that students combined both cultural and college food habits.

It has documented that vegetables and fruits are low in energy density because of their high water and fiber content. Therefore, adding them to a diet reduces its overall energy intake, thus, helping in weight management [33]. That could explain by two factors: 1) inadequate intake of these foods due to high cost in relation to bad economic conditions the students live in Palestine and specifically in Gaza and the siege imposed by Israeli military forces in addition to low income for the majority of families as well; 2) the unhealthy habits entitled in their consumption. Moreover, fruits usually taken as a dessert at the end of meals, thus, losing their "satiety effect" that tends to lower the overall energy intake of the diet. Although increased snacks of fast food, consumption often accused for increased prevalence of obesity, yet, a clear-cut relation between snacking and BMI is still unsettled.

Richards et al. [34] found that fruit and vegetable consumption among 18- to 24-year-old college students increased after a four-month implementation of newsletters based on the individual's stage of change, motivational interviewing sessions, and follow up contacts via e-mail. Contrary to what expected; Spanos and Hankey [35] examined the habitual meal and snaking patterns of university students' and found no correlation between BMI and snacking. On the other hand, de Graaf [36] reported that snacks (fast food) consumption may contribute to a positive energy balance and increased body weight.

The results of the current study were consistent with these of a study conducted by Papadaki et al. [37] re- 
vealed that significant decrease in the consumption of fruits, fresh and cooked vegetables, together with increased intake of sugar and fast foods were the major dietary changes reported for university students living away from the family home. In addition, it has suggested that the lack of experience in planning meals, and assuming responsibility for food purchasing and preparing for the first time are the main factors underlying the unhealthier dietary choices of these students.

\subsection{Student's Overall QoL Rating and Satisfaction with Their Health}

The current study revealed that $4.1 \%$ of students rated that their overall QoL were bad before the program compared to $1.4 \%$ \& $5.8 \%$ after the program for intervention and control group respectively. On the other hand, slightly less than one fifth of students rated that their overall QoL were very good compared to slightly more than third \& fifth thereafter for intervention and control groups respectively. In relation to how students were satisfied with their health slightly less than third of students rated that they perceive their health as bad compared to less than tenth \& slightly less than fifth thereafter for intervention and control group respectively. While slightly less than tenth of students, perceive that, their health was very good compared to slightly less than quarter \& slightly less than tenth thereafter for intervention and control groups respectively. The results of the current study also indicated that overall there was a statistically significant difference between the mean scores of rating QoL and health satisfaction in the intervention before and after the program and for each domain ( $\mathrm{p}$-value $\leq 0.05)$.

Researcher concluded that the mean scores of rating QoL and health satisfaction for after program was significantly greater than before the program and greater than control group for each domain (Table 5). That has to say half of students accepting their QoL. Moreover, more than half of them were satisfied and very satisfied in presence of either overweight/obesity but the improvements were apparent after the application of the health educational program and its sessions and they taking actions towards the behavioral changes of life style and eating habits and the warmth they receive from their families and friends.

\section{Conclusions}

According to results of the present study, it could be concluded that while the university students were overweight or obese they felt that they were in good health. Obese students were not fully aware of how severe their weight problem was, but were still likely to be losing weight while overweight students were aware that they needed to lose weight. In addition, those students did not participated frequently enough in physical activity, or at intensity sufficient to lose weight. They also experienced bad eating habits due to a lack of knowledge on proper diet. Thus, the main implication suggested by this study is that in every contact with adolescent students the CHN plays an important role in helping to educate those individuals on the severity of overweight/obesity, which should encourage them to eat healthy diet. And the proper weight loss strategies are necessary to lose weight.

In addition, because the health educational intervention program is convenient, inexpensive and easily accessible to students, it allows students to develop self-efficacy throughout the educational sessions and provides an opportunity for social support systems to develop through promotion of friendly team competition. It also promotes healthy eating and increases physical activity levels through modifying the unhealthy lifestyle, building self-efficacy, providing reinforcements, increasing behavioral capabilities, and providing self-regulation through goal setting processes and opportunities for vicarious learning.

\section{Acknowledgements}

First, several people have my immense gratitude. My sincere appreciation goes to Dr. Soheir Ali Bader el din, my research advisor and colleague, the chair of my dissertation committee, my mentor and friend. She has spent countless hours throughout this process guiding and encouraging me, keeping me on track, and helping me discover new possibilities. She has cultivated unexpected passions in me and made opportunities available to realize them. I would also like to thank the other members of my dissertation committee, Dr. Saneya Mohammed Rizk, has been especially important in providing assistance with my academic work and research, as well as offering timely words of encouragement that are so very much needed and appreciated. 


\section{References}

[1] Barness, L.A., Opitz, J.M. and Gilbert-Barness, E. (2007) Obesity: Genetic, Molecular, and Environmental Aspects. American Journal of Medical Genetics Part A, 143A, 3016-3034. http://dx.doi.org/10.1002/ajmg.a.32035

[2] Loscalzo, J., Fauci, S., Braunwald, E., Dennis, L., Kasper, H., Stephen, L. and Longo, D.L. (2008) Harrison's Principles of Internal Medicine. McGraw-Hill Medical.

[3] Viad, I. (2003) Obesity Costs UK economy £2bn a Year. British Medical Journal, 327, 1308-1308. http://dx.doi.org/10.1136/bmj.327.7427.1308-d

[4] Katzmarzyk, P.T. and Jenssen, I. (2004) The Economic Costs Associated with Physical Inactivity and Obesity in Canada: An Update. Canadian Journal of Applied Physiology, 29, 90-115. http://dx.doi.org/10.1139/h04-008

[5] Boutayeb, A. and Boutayeb, S. (2005) The Burden of Non Communicable Diseases in Developing Countries. International Journal for Equity in Health, 4. http://dx.doi.org/10.1186/1475-9276-4-2

[6] Van, P.H., Polder, J.J. and de Wit, G.A. (2008) Lifetime Medical Costs of Obesity: Prevention No Cure for Increasing Health Expenditure. PLoS Medicine, 5, e29.

[7] Chen, M., Wang, E., Yang, R. and Lion, Y. (2003) Adolescent Health Promotion Scale: Development and Psychometric Testing. Public Health Nursing, 20, 104-110.

[8] Stanhop, M. (2001) Handbook of Public and Community Health Nursing Practice a Health Promotion Guide. 2nd Edition, Mosby, Philadelphia, 53-303.

[9] Haslam, D. (2007) Obesity: A Medical History. Obesity Reviews, 8, 31-36. http://dx.doi.org/10.1111/j.1467-789X.2007.00314.x

[10] Caballero, B. (2007) The Global Epidemic of Obesity: An Overview. Epidemiologic Reviews, 29, 1-5.

[11] World Health Organization (2000) Obesity: Preventing and Managing the Global Epidemic. Technical Report Series No. 894, WHO, Geneva.

[12] Peter, G., Ian, D., Michael, J. and William, H. (2005) Clinical Obesity in Adults and Children: In Adults and Children. Blackwell Publishing.

[13] Musaiger, A.O. (2003) Socio-Cultural Factors Affecting Obesity in the Arab Countries. Technical Report, Bahrain Centre for Studies and Research, Bahrain.

[14] Ministry of Health (2005) Palestinian Health Care System the Status of Health in Palestine. Annual Report 2005.

[15] Al-Isa, A.N. (1999) Dietary and Socio-Economic Factors Associated with Obesity among Kuwaiti College Men. British Journal of Nutrition, 82, 369-374.

[16] Al-Malki, J.S., Al-Jaser, M.H. and Warsy, A.S. (2003) Overweight and Obesity in Saudi Females of Childbearing Age. International Journal of Obesity, 27, 134-139. http://dx.doi.org/10.1038/sj.ijo.0802181

[17] Al-Turki, Y.A. (2007) Overweight and Obesity among University Students, Riyadh, Saudi Arabia. Middle East Journal of Family Medicine, 5.

[18] El-Qudah, J.M., Al-Widyan, O.K., Alboqai, A.A. and Suleiman, J.M. (2008) Fat Soluble Vitamins (A, E and K) Intake among a Sample of Jordanian University Students. World Applied Sciences Journal, 5, 252-257.

[19] Yahia, N., Achkar, A., Abdallah, A. and Rizk, S. (2008) Eating Habits and Obesity among Lebanese University Students. Nutrition Journal, 7, 32.

[20] Al-Rukban, M.O. (2003) Obesity among Saudi Male Adolescents in Riyadh, Saudi Arabia. Saudi Medical Journal, 24, 27-33.

[21] Poirierha, P., Giles, T.D., Bray, G.A., Hong, Y.L., Stern, J.S., Pi-Sunyer, F.X. and Eckel, R.H. (2006) Obesity and Cardiovascular Disease: Pathophysiology, Evaluation, and Effect of Weight Loss. Arteriosclerosis, Thrombosis, and Vascular Biology, 26, 968-976. http://dx.doi.org/10.1161/01.ATV.0000216787.85457.f3

[22] Mo-Suwan, L., Tongkumchum, P. and Puetpaiboon, A. (2000) Determinants of Overweight Tracking from Childhood to Adolescence: A 5y Follow-Up Study of Hat Yai School Children. International Journal of Obesity, 24, 1642-1647. http://dx.doi.org/10.1038/sj.ijo.0801432

[23] Terres, N.G., Pinheiro, R.T., Horta, B.L., Pinheiro, K.A. and Horta, L.L. (2006) Prevalence and Factors Associated to Overweight and Obesity in Adolescents. Revista de Saúde Pública, 40.

[24] Khader, Y., Irshaidat, O., Khasawneh, M., Amarin, Z., Alomari, M. and Batieha, A. (2008) Overweight and Obesity among School Children in Jordan: Prevalence and Associated Factors. Maternal and Child Health Journal, 13, 424431.

[25] Al Sabbah, H., Vereecken, C., Abdeen, Z., Coats, E. and Maes, L. (2008) Associations of Overweight and of Weight Dissatisfaction among Palestinian Adolescents: Findings from the National Study of Palestinian Schoolchildren 
(HBSC-WBG2004). Journal of Human Nutrition and Dietetics, 22, 40-49. http://dx.doi.org/10.1111/j.1365-277X.2008.00901.x

[26] Layton and Julia (2006) Is a Lack of Sleep Making Me Fat? HowStuffWorks.com.

[27] National Sleep Foundation (2005) Sleep Facts and Stats. http://www.sleepfoundation.org/hottopics/index.php?secid=9\&id=34

[28] Kotler, S. (2005) The Perils of Higher Education. Psychology Today, 38, 64-70.

[29] Pilcher, J.J. and Walters, S.S. (2002) How Sleep Deprivations Affects Psychological Variables Related to Students' Cognitive Performance. Journal of American College Health, 46, 121-126. http://dx.doi.org/10.1080/07448489709595597

[30] Haines, D.J., Davis, L., Rancour, P., Robinson, M., Neel-Wilson, T. and Wagner, S. (2007) A Pilot Intervention to Promote Walking and Wellness and to Improve the Health of College Faculty and Staff. Journal of American College Health, 55, 219-225. http://dx.doi.org/10.3200/JACH.55.4.219-225

[31] Hart, C.L., Hole, D.J., Lawlor, D.A. and Smith, G.D. (2007) How Many Cases of Type 2 Diabetes Mellitus Are Due to Being Overweight in Middle Age? Evidence from the Midspan Prospective Cohort Studies Using Mention of Diabetes Mellitus on Hospital Discharge or Death Records. Diabetic Medicine, 24, 73-80. http://dx.doi.org/10.1111/j.1464-5491.2007.02016.x

[32] Villareal, D.T., Apovian, C.M., Kushner, R.F. and Klein, S. (2005) Obesity in Older Adults: Technical Review and Position Statement of the American Society for Nutrition and NAASO, the Obesity Society. Obesity Research, 13, 1849-1863. http://dx.doi.org/10.1038/oby.2005.228

[33] Rolls, B.J., Ello-Martin, J.A. and Tohill, B.C. (2004) What Can Intervention Studies Tell Us about the Relationship between Fruit and Vegetables Consumption and Weight Management? Nutrition Reviews, 62, 1-17. http://dx.doi.org/10.1111/j.1753-4887.2004.tb00001.x

[34] Richards, A., Kattelmann, K.K. and Ren, C. (2006) Motivating 18- to 24-Year-Olds to Increase Their Fruit and Vegetable Consumption. Journal of the American Dietetic Association, 106, 1405-1411. http://dx.doi.org/10.1016/j.jada.2006.06.005

[35] Spanos, D. and Hankey, C.R. (2010) The Habitual Meal and Snacking Patterns of University Students in Two Countries and Their Use of Vending Machines. Journal of Human Nutrition and Dietetics, 23, 102-107. http://dx.doi.org/10.1111/j.1365-277X.2009.01005.x

[36] De Graaf, C. (2006) Effects of Snacks on Energy Intake: An Evolutionary Perspective. Appetite, 47, 18-23. http://dx.doi.org/10.1016/j.appet.2006.02.007

[37] Papadaki, A., Hondros, G., Scott, J.A. and Kapsokefalou, M. (2007) Eating Habits of University Students Living at, or away from Home in Greece. Appetite, 49, 169-176. http://dx.doi.org/10.1016/j.appet.2007.01.008 
Scientific Research Publishing (SCIRP) is one of the largest Open Access journal publishers. It is currently publishing more than 200 open access, online, peer-reviewed journals covering a wide range of academic disciplines. SCIRP serves the worldwide academic communities and contributes to the progress and application of science with its publication.

Other selected journals from SCIRP are listed as below. Submit your manuscript to us via either submit@scirp.org or Online Submission Portal.
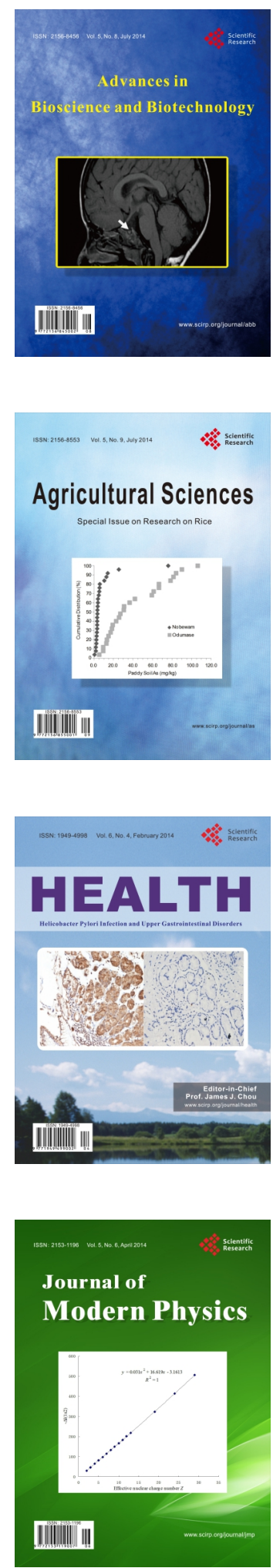
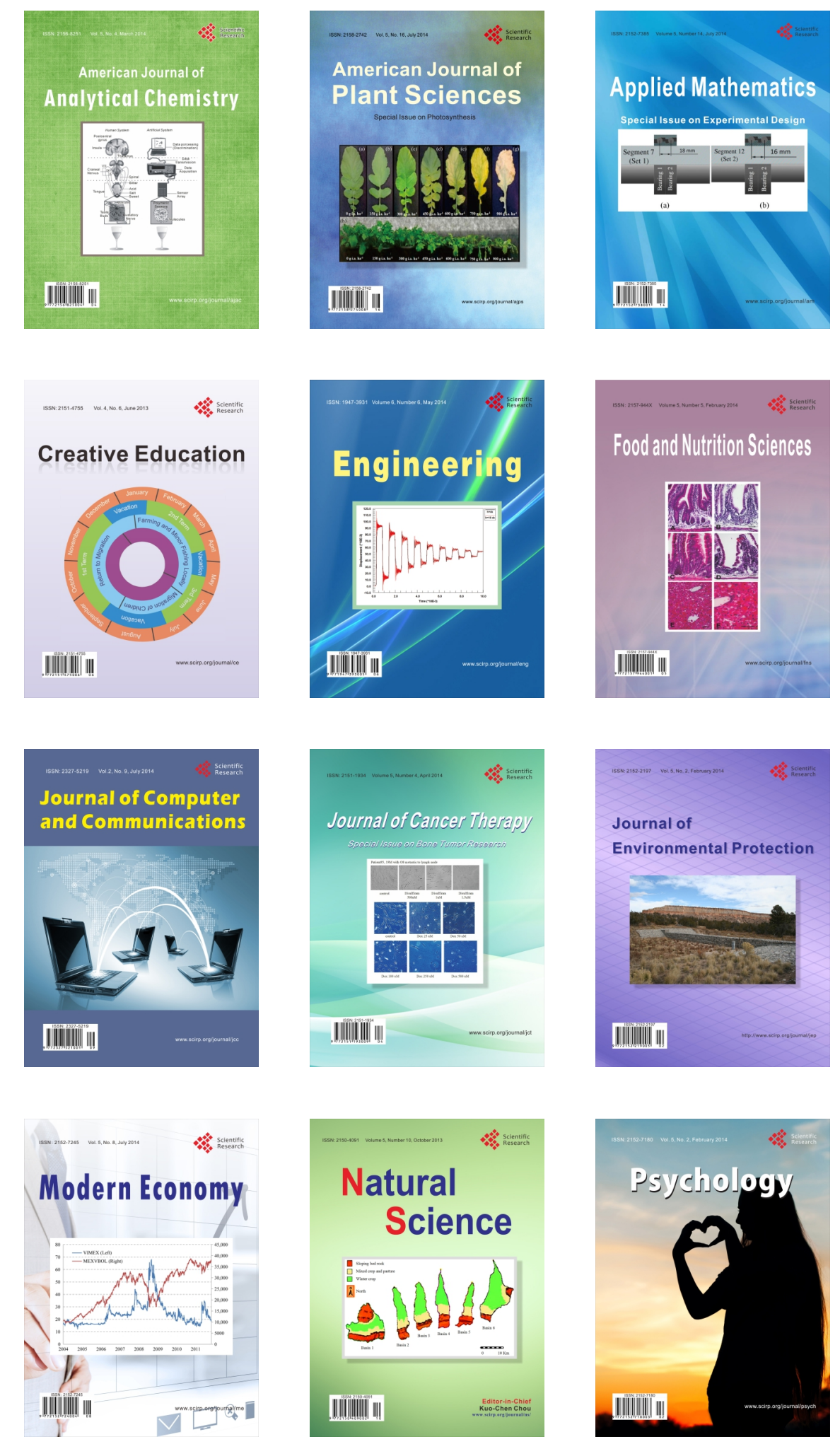